\title{
Geographic Information Portals: Maldives Tourism Perspective
}

\author{
Somnath Chaudhuri ${ }^{1}$
}

\begin{abstract}
In the era of Web 2.0, Geographic Information Portals (Geoportals) play a dynamic role in customizing online spatial information search and sharing. Geoportals combine the power of Web GIS with the ubiquity of the internet. Tourism industry has widely adopted Web GIS and geoportals in order to improve service management, transparency in information sharing and promotion. This research paper focuses on the fact that, geoportals has a huge potential in the field of tourism management. The present study has been conducted to analyze the current online available information and the tourist inflow for the Republic of Maldives. It discusses about the basic architecture and techniques of providing additional online information using customized geoportals and their potential benefits. The final section of this paper, suggests strategic implementation of geoportals for effective tourism management and promotion in Maldives.
\end{abstract}

Keywords - Web 2.0, GIS, Geoportals, Mashup, SDI, CSW

\section{INTRODUCTION}

$\mathrm{P}$ EOPLE and organizations have always exchanged spatial geographic information. But with the advent of internet and World Wide Web the practice has increased exponentially. Web 2.0 has created a global open platform, popularly known as "the domain of mass amateurization". It has dramatically transformed the static websites to interactive dynamic web platforms. This second generation of Web has changed webpages to more like an application, where anyone having access to internet, can update and share spatial information. Today's web user can create content on the web both collaboratively and individually, allowing for a personalized web experience through wikis, blogs, podcasts, photo sharing, and other technologies. GIS and mapping applications have both benefited from and contributed to these trends, collectively called "Web 2.0" [1]. One important Web 2.0 technology is the Mashup tool. On the Web GIS context, a Mashup is the method of merging heterogeneous sources of data, both spatial and non-spatial, into a single integrated spatial display. Nowadays, the free availability and wide accessibility of web map services (e.g. google maps) and geodata have democratized the creation and dissemination of geographical content and services [2]. According to mashable.com, more than $40 \%$ of mash-up applications use google maps' API. This is not surprising when considering

Somnath Chaudhuri ${ }^{1}$ is with the Faculty of Science, Maldives National University, Republic of Maldives (phone: +960 7626371; email:som.rtc@gmail.com). that the $80 \%$ of all digital data generated today includes geospatial referencing [3]. With the development of semantic web technologies, data mining methods, geo-referenced web applications and cloud technology the World Wide Web has transformed into customized Geoportals. The word "portal" literally means entrance or gate. The dynamic websites that serve as the gateway to other websites or geospatial information are called as Geographic Information Portals or Geoportals. It basically provides categorized links to multiple online resources. Since mid-1990s, when the content available over the internet has increased exponentially the Web users felt the utter need for an improvised searching mechanism to reduce the time complexity of online search. Web Portals provide an effective and swift technique to store the resources in a distributed platform with direct means of indexing and categorizing. It helps in retrieving the searched data in shorter span of time. According to Tang, Web portals saved the web from being blogged down in a sea of data and have played a significant role in the success and popularity of the Web [4]. The portals indicated by a prefix "geo" are those portals which specialize in storing and retrieving geospatial information. A geoportal, also referred to as a spatial portal, is a website that provides a single point of access to geospatial data, Web services, and other geospatially related resources. Put more simply, a geoportal is a website where geospatial resources can be discovered [5].

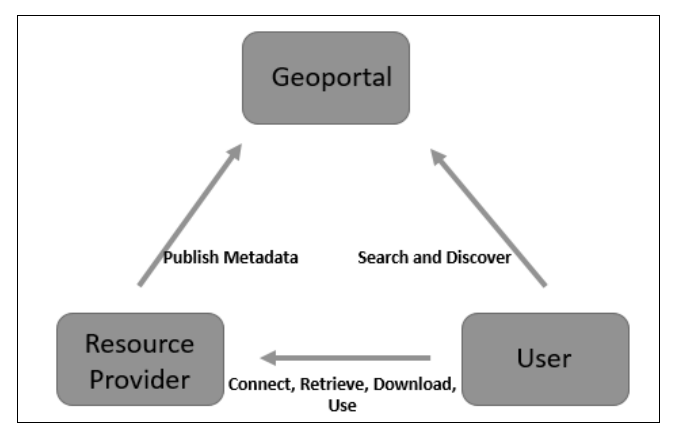

Fig. 1 Gateway between Geoportal resource providers and users

But the information or resources available are not maintained or updated by a single resource provider; it is the collaborative effort of diversified online geospatial participants integrating heterogeneous resources. Figure 1 depicts the relationship between the geospatial resource providers and the users availing the service of geoportal. Geoportals act as a bridge or gateway between the information providers, who own the information and the 
users, who need it. The resource providers usually share the "data about the data" called metadata in the form of links or as data packages. The users in search of relevant data or information will browse to the geoportals. The effective data mining methods, geo-referenced web applications and distributed database management system will retrieve relevant information just on a click. The Alexandria Digital Library (ADL) and U.S. National Geospatial Data Clearinghouse (NGDC) are among the early examples of operational geoportals. ADL is an online geolibrary which includes digitized maps, images, and textual materials. Users are able to retrieve materials from the library on the basis of information content as well as by the reference to spatial location [6], [7]. Over the years, geospatial data has been collected, processed and stored by many organizations. But there was no common global platform for sharing those data. As a result isolated pools of information were getting piled up; leading to redundant, under-used data. In the year 1990 United States gave a head start on developing Spatial Data Infrastructure (SDI). SDI is basically the technology to share all those dispersed set of data into a common global platform. According to Pinde Fu, SDI is basically the technology, policies, standards and human resources necessary to acquire, process, store, distribute and improve the use of geospatial data [8]. With geoportals, any search time over the internet can be reduced from days to seconds. On the Web GIS context, geoportal is the Web 2.0 technology of merging multiple sources of data, both spatial and non-spatial, storing in a customized manner and retrieving as a single integrated spatial display. The present study discusses the basic architecture of the Geoportals and its application in tourism management and promotion.

\section{GEOPORTAL ARCHITECTURE}

Geoportal is an interactive collaborative Web 2.0 application. It provides an array of functionalities and modules for different levels of users.

\section{LEVEL OF USERS:}

Based upon the accessibility of the available functions, geoportals can be categorized into three levels of users: Administrators, Publishers and Common Users.

Administrators mainly manage the content or resources in the geoportal. Besides they can manage the accounts of the other two types of users; control the authentication of metadata publication and manage security of the entire portal. Publishers are the fuel suppliers of the system. They provide resources by creating, publishing and updating metadata and control the accessibility rights (private or public) of the metadata.

Common Users accounts are authenticated by the administrators. Depending upon the accessibility right for different resources they can search for contents, view or can download metadata information. They can create composite maps if and when required with the help of an interactive map viewer. Figure 2 depicts the distribution of the functions among the three levels of geoportal users.

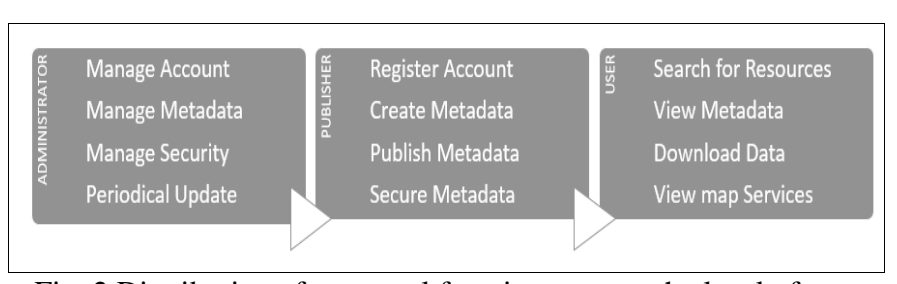

Fig. 2 Distribution of geoportal functions among the level of users

\section{METADATA CONCEPT:}

The speed of geoportals lies in the fact that, it doesn't play with real mass of data. The key element responsible for the speed of geoportals is Metadata. What is this metadata and how it enhances the speed of online search? The definition of metadata is "data about data". When a normal user is searching for some geo-referenced online information, metadata instead of retrieving the chunk of real data, it refers to the original information related to the search via URL or refers to some relevant web services or to other geospatial resources. Geospatial metadata, usually represented in XML format, represents the "who, what, when, where, why and how" of a piece of geospatial data or other resource [9]. The series or group of metadata entities is called Collection-level metadata and when it represents a single entity it is known as Object-level metadata. In both types of metadata the basic common characteristics are, spatial references, temporal information, distribution information, source of resources, evaluation of resources, use of resources etc. But these characteristics restrict them in the domain of static, noninteractive Websites. In the era of Web 2.0, everyone who is willing to share their content should be able to do so. With the increased ease of sharing, comes demand for an increased ease in describing the item to be shared. This leads to the need for metadata 2.0, which should be user-centric, easy for contribution to create, and easy for users to understand [10], [11]. Tags used in almost all social sites is an example of metadata 2.0. Tags allow the contributor to quickly share information and let users quickly evaluate resources that they are looking for. From professionals' point of view, tags are often incomplete and informal. But different types of users need different types of metadata. While metadata 1.0 is still important in enabling professionals and organizations to document their GIS information assets, and to discover and evaluate the applicability of assets for certain users, metadata 2.0, such as tags, encourages broad participation in the sharing of information and is a strategy that can be adopted by geoportals in many situations [8].

\section{N-TIERS ARCHITECTURE:}

As discussed in the beginning of this section, any geoportal has at least three levels of users. But in the implementation model and the decomposition of the entire application, geoportals consist of $n$-tiers subsystems and architecturally significant implementation elements. Each tier is responsible for explicit tasks. When the tasks are accomplished, the result is handed over to the next tier. Based upon the nature of the tasks specific technologies are chosen for each tier. The whole architecture consists of 3 main parts: the Presentation tier, 
the Application tier and Service tier. The Presentation tier contains the components that run on the client machine and handles simple tasks such as input validation, layout and map presentation. The Application tier contains components that run on the server and handles more complex tasks such as processing the search logic and retrieving data from persistent objects. Service tier contains the servers that provide the Database Service, Web Map Service (for the map used for discovery) and Discovery Services from the Member States. A consolidated model repository, feature concept dictionary, and glossary are being maintained to support the consistent specification development and potential further reuse of specification elements [12]. Figure 3 represents the block diagram of n-tier geoportal architecture and their respective sub layers.

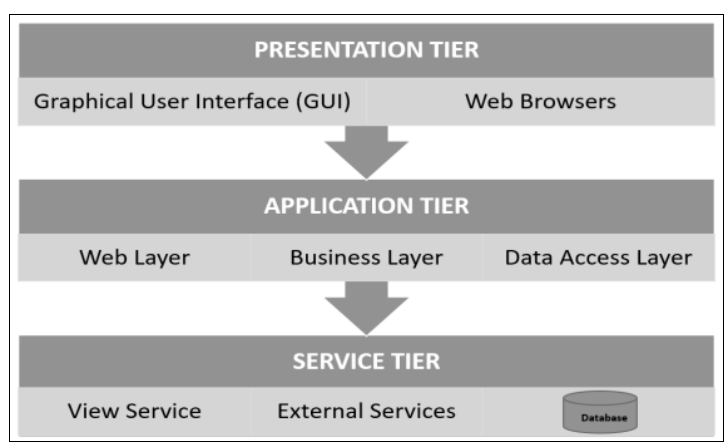

Fig. 3 Geoportal N-tier Architecture

\section{GEOPORTAL CATALOG:}

On the basis of metadata searching techniques, the geoportal architecture has been categorized namely, Distributed and Centralized catalog types.

Distributed geoportal catalog has to perform distributed searches to accomplish the user's request. Figure 4 illustrates the work flow of a geoportal in distributed catalog mode. In this type of architecture, individual participants maintain their own metadata catalog server, called a node.

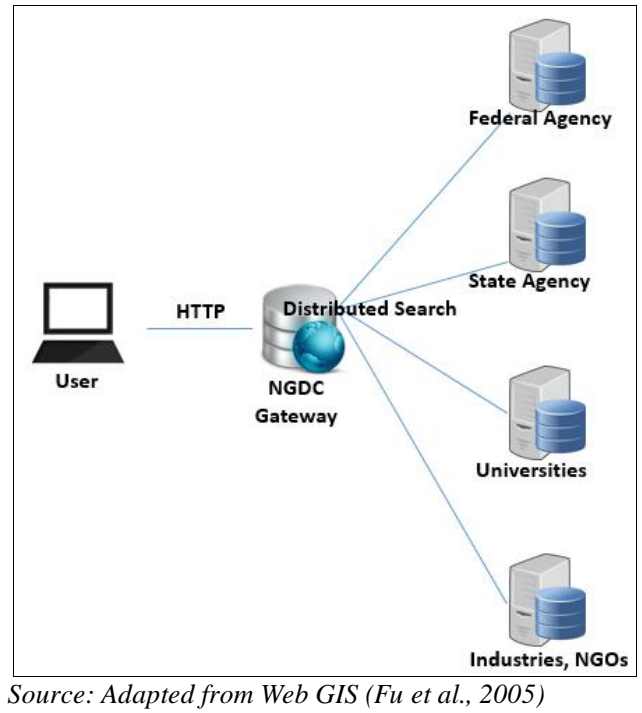

Fig. 4 Distributed Geoportal architecture (e.g. NGDC Geoportal)
Each node is registered to a central gateway server. When a query is fired by the user the gateway server establishes connection with the selected nodes and passes the metadata query. Individual nodes process them and forward the retrieved results. The gateway server then merges the search results and displays back to the user. Finally, the user can view the relevant metadata records. But there are few limitations for the distributed catalog architecture: the working principle depicts that it has limitations in speed, besides it requires high participant providers. To get rid of the problems in distributed architecture leading to difficulties in global search the centralized architecture came into play. The architecture of a centralized geoportal catalog is depicted as in Figure 5.

For large portals like ArcGIS, that involve multiple providers (each with its own metadata catalog), a centralized catalog can be a good strategy. Each of the participant's catalogs can be loaded into the central catalog through metadata harvesting or synchronization. Each provider can individually register to the central server. Web portal automatically connects to a registered catalog, retrieves all its metadata on the first visit, and on subsequent visits retrieves only updated data [8]. This mode of architecture tends to overcome the limitations inherent in distributed architecture. Thus, providers an enhanced performance by faster global searches and low requirement for participant.

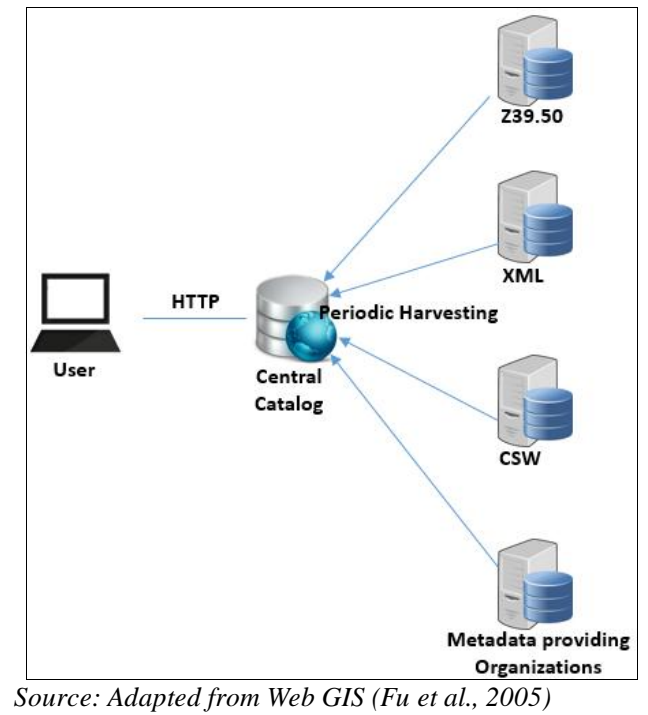

Fig. 5 Centralized Geoportal architecture (e.g. ArcGIS Geoportal)

\section{GEOPORTALS IN TOURISM}

Tourism is defined by the World Tourism Organization (NSCB , 2004), as the act of travelling for the purpose of recreation and the provision of services for this act. Tourism is a vital part of the global economy. It helps countries that are poor in material wealth but enriched in heritage, culture, history to utilize their unique characteristics as a revenuegenerating source. This business involves many socioeconomic activities like promotion and advertising tourist spots and destinations, providing effective transport facility, 
fooding-lodging, entertainment etc. which tends to encourage the overall development of infrastructures that benefits the host nations [13]. Information and communication is an integral part of any service industry, tourism is not an exception. Information Technology breaks the geographical boundaries and share information with the global audiences. It integrates tourism products and requirement of the tourists. Information and Communication Technology (ICT) can lead tourism to emerge as a new mantra for alternative economic development [14]. The technological innovations started in the 1970s when the main airlines set up CRSs (Computerized Reservation Systems), with the strategic aim of building a global distribution network for their products. Connecting travel agencies to the CRSs set off a process of distribution automation involving an ever-increasing number of tour operators, carriers, and car hire firms, individual hotels, hotel chains, and other hospitality firms [1]. Geographical Information System (GIS) has been extensively used for tourism promotion and management. It was in use for GIS data design and collection, management of database design and application of tourism analysis and problem solving. The GIS technicians and researchers started research on how to share the GIS features online, rather than using it as a standalone system. Since 1993, the Web GIS started evolving rapidly. Today's web user can create content on the web both collaboratively and individually, allowing for a personalized web experience through wikis, blogs, podcasts, photo sharing, and other technologies [13]. During the initial considerations related to travel issues, the first query is directed towards geographic and spatial information about the places the potential tourist want to reach. According to mashable.com, more than $40 \%$ of mash-up applications use google maps' API. This is not surprising while considering that the $80 \%$ of all digital data generated today includes geospatial referencing [3]. Many organizations are developing geoapplications to enhance their business operations and transform their business models. The tourism industry is not an exception; because geospatial data and digital maps are the lifeblood of tourism. Tourism by nature involves the transfer of people to places away from home; and all tourism activities take place in certain geographical areas. Indeed, GIS and currently, Web GIS and geoportals are widely adopted in tourism for several purposes, such as: trip planning, visitors' management, tracking tourists' behavior, online bookings, location-based services, management and measurement of destinations' carrying capacity, crisis management and for providing localized personalized content to customers [15]. In the year 2007, Fajuyigbe and Balogun presented a work on Web-Enabled GIS as a potential tool for sustaining tourism in western Nigeria. It discusses how a Web-based GIS was used as a potential tool for rendering and analysis of tourism information for efficient management, promotion and sustainability of tourism in Nigeria [16]. In the era of Web 2.0 any person having access to internet can create or update content on the web both collaboratively and individually. That leads to the volume of content available over the internet to bloom up exponentially. That points to the need for some mechanism which can customize the search and make it faster and more effective. Web users were trying to find out technical solutions to find the content they want, just on a click. But it was not easy to execute a query and retrieve the relevant result from the ocean of Web Information just on a click. Like the most common queries for any potential tourist can be, where the place is exactly located, what is the distance, what are the special features it has etc. To retrieve all the information from the pile of geospatial data is not so easy. But Geoportals provide an easy direct means of indexing, ordering, and displaying both spatial and nonspatial information. Throughout the globe, geoportals has become an indispensable unit of tourism. Geoportals provide semantic web technologies, data mining, geo-referenced spatial methods and cloud based technologies. All of these acts as a virtual personal assistant who knows the tourist's profile, access information through Web in order to best meet the requirements and represent information in desired format [17]. As more and more travelers wish to create their personalized trip itineraries, the provision of geographical information and services is an unavoidable necessity for travel websites. The current evolution of geoportals and geocollaborative portals present numerous opportunities for making the trip planning process less complex and time consuming, more efficient, social, collaborative and enjoyable for travelers [18]. The use of geoportals and the provision of web map services has also become a widespread standard for numerous tourism websites and e-tourism applications. By using web map services, tourists can more quickly, precisely and accurately find all travel information for organizing their itineraries [19]. Geoportals offer a single point of access for searching and for downloading Web GIS data from multiple heterogeneous sources. These fast, cheap, collaborative and multi-layer web map services empower tourists with new trip planning geospatial tools and information. Geoportals typically retrieve the data from heterogeneous sources and display it in the form of a map. The map can be static or interactive. In case of tourism, maps are usually used in selecting the tourist destinations and in planning travel and stay. Potential tourists use maps to navigate on or before travels and for planning about the trip. Interactive online maps provided by geoportals exploit the two dimensional capabilities of human vision and represent the information in an effective, precise and "easy to read" manner. Small countries enriched in tourism factors have already identified the positive impact of having national Geoportals. Luxembourg, one of the smallest sovereign states in Europe decided to have an official geoportal in the year 2008. In the country, the Administration of Cadastre and Topography (ACT) is responsible for the creation, updating and delivery of the major geospatial data. The data includes, the cadastral map and its subsets, the different topographic and cartographic maps and databases, the digital terrain model etc. The national geoportal gives access to different thematic mapping windows, result of cooperation between different key geodata-stakeholders e.g. the agricultural map portal, 
biodiversity map portal, water mapping window, tourism map viewer, mapping window for professionals [20].

A snapshot of Luxembourg National Geoportal (Theme Tourism) is depicted in Figure 6.

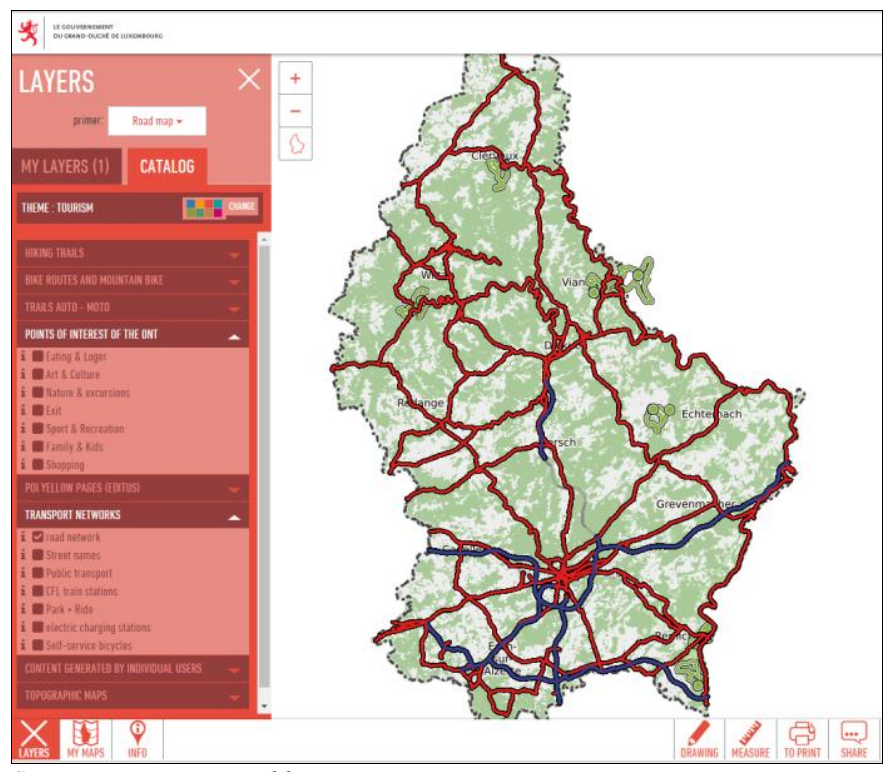

Source: map.geoportail.lu

Fig. 6 Geoportal Example (Luxembourg-Theme Tourism)

Any potential tourist can access this national geoportal. Categories like, Hiking trails, Bike Routes and Mountain Bike, Points of Interest, Transport Networks, Topographic Maps etc. are designed mainly for the tourism theme of the national geoportal of the country. To add more value each of the categories are classified into subcategories like: Eating and Loger, Art and Culture, Nature and Excursions, Sports and Recreation, shopping etc. are designed under the category Points of interest. All these are metadata repository providing detailed information under each category just on click with geospatial representation. The geoportals also have interactive and collaborative features of Web 2.0. Any user can create his own map, might be a bike or a hiking trail or might be just a shopping and a café stroll. It can be updated in the portal using "Content Generated by Individual Users" and it will get added in the portals metadata repository.

Another informative geoportal example is the national geoportal of Valencia, Spain. It is one of the most famous tourist destination because of its heritage of ancient monuments, views and cultural attractions and definitely the picturesque sea beaches. A snapshot of Valencia National Geoportal (Theme Tourism) is depicted in Figure 7. This particular geoportal is actually a Mashup application, where the base map in powered by Google and the location tags are generated by Web 2.0 application. But it is not as interactive as the previous one. The users can only perform customized search, filter out options and date specific activities. Still it is helpful for any potential tourist. Few other examples from countries like:

Philippines (www.geoportal.gov.ph/apps/tourism/),

Rwanda (http://rwandageoportal.rnra.rw),
India (http://bhuvan.nrsc.gov.in/tourism) are quiet impressive.

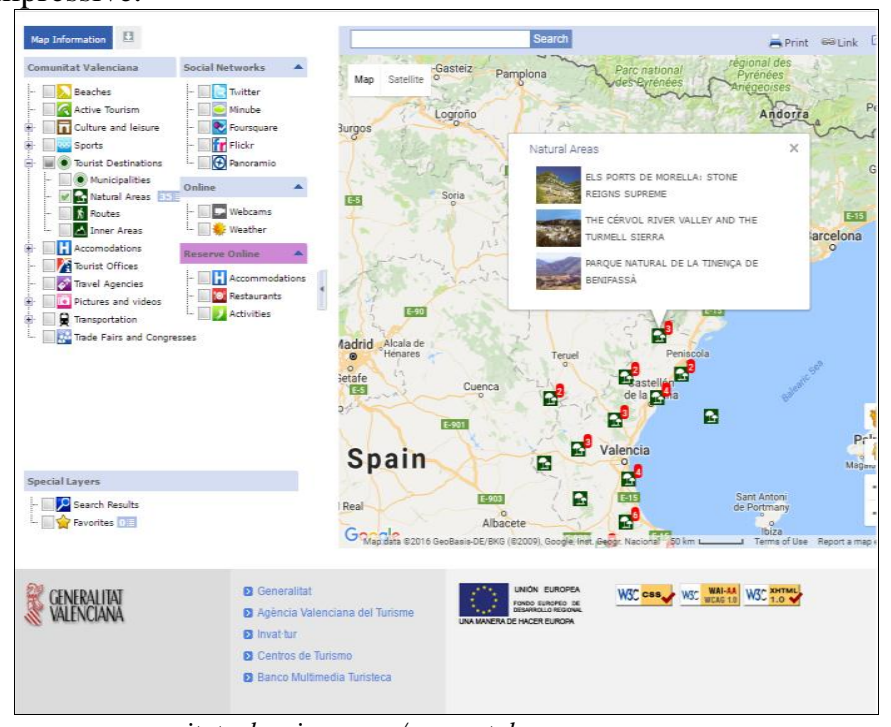

Source: en.comunitatvalenciana.com/geoportal-en

Fig. 7 Geoportal Example (Valencia Geoportal)

According to Turner (2006), the implications of web 2.0 on geoportals lead to a new era called neogeography, and several recent publications (e.g. Erle, Gibson, and Walsh, 2005; Scharl and Tochtermann, 2007; Sigala \& Marinidis, 2009) analyze numerous case studies illustrating how the two features of web 2.0 (collective intelligence and social networking) have revolutionalised the creation and diffusion of geoportals [21]. In the year 2005 Tait identified four major functionalities of geoportals related to tourism. He suggested to expand the original factors further to include the collaborative and social capabilities of Web 2.0 in tourism management. These four functions of geoportals, namely Search, Mapping, Publishing and Administrative Capabilities has great implications on trip planning and decision making process. They act as virtual guide and planning tool for the potential tourists. Table 1 below highlights on the Geoportal Web 2.0 functions and their respective implications [22]:

TABLE I

GEOPORTAL WEB 2.0 FUNCTIONALITY

\begin{tabular}{|c|c|c|}
\hline Functions & $\begin{array}{l}\text { Web } 2.0 \text { enhanced } \\
\text { Functions }\end{array}$ & $\begin{array}{l}\text { Web 2.0 Tools supporting the } \\
\text { functions }\end{array}$ \\
\hline Search & Social Search & Tag searching, Vertical Meta \\
\hline & & $\begin{array}{l}\text { Search, Link Search, } \\
\text { Bookmarking etc. }\end{array}$ \\
\hline Mapping & Social Mapping & $\begin{array}{l}\text { Geo-Tags, Hotspots, Point of } \\
\text { Interest etc. }\end{array}$ \\
\hline Publishing & $\begin{array}{l}\text { Collaborative } \\
\text { Publishing }\end{array}$ & $\begin{array}{lll}\text { RSS, Web-casting, } & \text { Wikis, } \\
\text { Blogs, } \quad \text { Forums, } & \text { Social } \\
\text { Networking etc. } & \end{array}$ \\
\hline Administration & Mashup & $\begin{array}{l}\text { APIs, Mashup, Content } \\
\text { publishing through APIs etc. }\end{array}$ \\
\hline
\end{tabular}

Overall, geoportals have significantly changed the way how potential tourists plan their trips by enabling them to search, contribute, share experience on top of an interactive map. 


\section{TOURISM IN MALDIVES}

Republic of Maldives is located on the south and southwestern region off the coast of India. The country consists of about 1190 coral islands grouped into 26 natural atolls. Tourism contributes the largest section of the economy in Maldives. Tourism began in Maldives in late 1900's. In the year 1972 the first resort started working and ever since then tourism has flourished in this island nation. Because of the crystal clear lagoons, azure warm ocean with an undisturbed exotic coral and marine life Maldives has become one of the most popular marine tourist destination. It helps in earning foreign revenues and creating employment in the country. According to the World Travel and Tourism Council, direct contribution of Travel \& Tourism to Maldives GDP in 2015 was MVR 22,069.7mn (52.4\% of GDP). This is forecast to rise by $2.2 \%$ to MVR $22,545.3 \mathrm{mn}$ in 2016 . Leisure travel spending (inbound and domestic) generated $97.4 \%$ of direct Travel \& Tourism GDP in the year 2015 compared to $2.6 \%$ for business travel spending. The Leisure travel spending is expected to grow by $3.7 \%$ in 2016 to MVR 46,092.1mn, and rise by $3.6 \%$ pa to MVR $65,852.2 \mathrm{mn}$ in 2026 [23]. Figure 8 represents the gradual increase in tourist inflow in Maldives. But in the year 2009-2010 the annual growth rate was approximately $19 \%$ which changed to $15 \%$ in the year 2015 2016 [24].

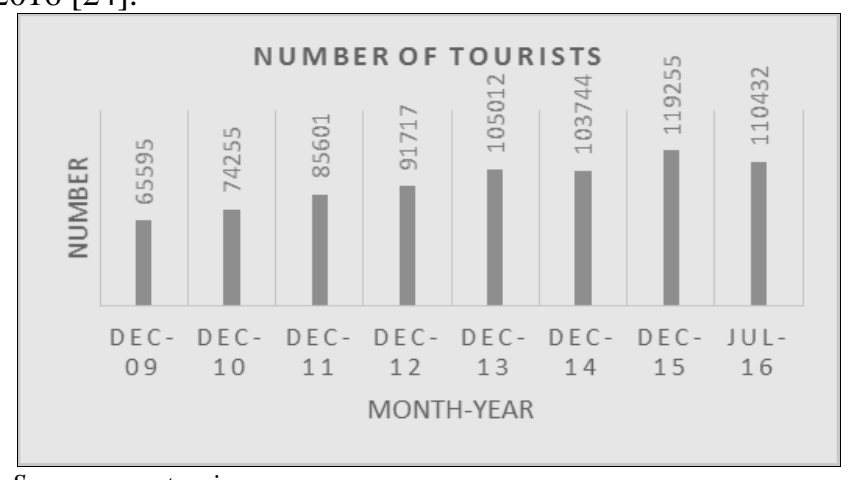

Source: www.tourism.gov.mv

Fig. 8 Tourist Inflow in Maldives

Today, Maldives is a popular tourist destination, with a number of international brand names in its tourism assortment. Most of the resorts in Maldives are capable of providing state-of-the art facilities and services, entertainment and high-tech telecommunication services [25].

\section{MALdives TouRISM: ONLINE AVAILABLE RESOURCES}

The Ministry of Tourism, Republic of Maldives has a compact website dissipating online tourism information. The website has regular updates and has the set of metadata repository like, past years tourist inflow details, annual publications etc. In terms of static information it is impressive. But in the era of Web 2.0 the potential tourists long for interactive geoportals. They can plan their trips if they are able to search, contribute, share experience on top of an interactive map. The Mapping of the Maldives and Climate Change (MMCC) project, was a grant assistance from the French Global Environment Fund with the overall objective of the development of large scale mapping of the Maldives. In the final symposium for MMCC project, the importance of mapping in order to understand the effects of climate change and to prioritize specific adaptation measures, and the need to do it continuously and consistently was highlighted. It was also pointed out that, the limited amount of accurate data available regarding the geography of Maldives, as the volume of data will have various implications on the adaptations measures. Thus, there is need to continue the process of mapping and apply the information to monitor and take better adaptation measures [26].

The right to information is an important aspect of democratic accountability and promotes transparency and encourages full participation of citizens in the democratic process (Commonwealth Law Ministers, 2002). Keeping these words in notice, Maldives Government has taken an einitiative for customized online information sharing. ISLES (www.isles.egov.mv) is the result of it. It is an interactive online application designed to provide information on the socio-economic activities in each island. It has been developed to improve government transparency and accountability by providing decision-makers and the public with a user-friendly and comprehensive account of development activities in all the islands of the Maldives. ISLES provides island level information on specific projects that have been funded both by the Government of Maldives and other international donors [27]. The metadata repository and the customized filtering and search options definitely provide information on the socio-economic activities in each island. The page has an interactive feature called Feedback, where the government of Maldives has requested all relevant bodies to update the information contained in the website. But it can accept textual comments. The users do not have privilege to update any geospatial information on an interactive map. The site also contains a huge metadata Map repository; detailed map of all the provinces and individual islands. But all are static maps. Any mashup applications' features are not available in these maps. In terms of Government project report repository it is effective. But for the millions of tourists who are visiting this beautiful island nation every year, this e-initiative is not relevant and effective. For example, a potential tourist while searching over the web about Maldives he will definitely search for the resorts, hotels, the points of interest or the transport facilities. These features are not available in ISLES. It maintains a comprehensive account of development activities in all the islands of the Maldives. According to the annual report of the Ministry of Tourism (2015), at the end of year 2014, there are total 111 resorts/marinas in different islands of this island nation [28]. Most of the island resorts have their individual informative websites. The websites have static maps of their respective islands. Few have embedded Google maps too. These websites contain specific information only about their resorts or the island. Some websites provide places of interest in the capital city of Male`. They are interactive only in terms of reservation and feedback, but not in geoportal mode. Maldives Tourism related websites like, 
www.atollsofmaldives.gov.mv,

www.mtdc.com.mv, www.matimaldives.com, www.maldivesdir.com/travel, has taken initiative to provide online Maldives travel and tourism information. But most of the websites act in half-duplex mode; the users have to depend only on the static information provided by the website administrators. They are noncollaborative and non-interactive. In this era of Web 2.0, a website should not be a static page in the browser, but a dynamic platform for customized data where the users can generate and update their own experiences. There are few geo-tagged websites like www.measuremaldives.com, www.eatolls.com, www.raajjemap.com etc. Distance and bearing calculator in measuremaldives.com provides a huge metadata repository catalog with user-controlled filtering options. Users can get an estimation of the distance between two islands in the same atoll, or in different atolls. It is really convenient to get an idea about the geographic distance between two islands or atolls. But it is missing the interactive and collaborative geoportal features. Local users don't have the right to update or upload any new information in the website. Users have to depend on the static information sited by the website. One decent example of geo-tagged website in Maldives is, Eatolls. This website contains geoportal features like filtering metadata repository. Figure 9 depicts a snapshot of Eatolls website where the user can search by parameter, "island resorts" and it will display the resorts of Maldives. The base map is powered by Google, but it has interactive mashup applications embedded in its geoportal catalog with metadata repository. The website also provides detail transport information about the resorts. Google Maps provides direction between two locations either by various land route or by flight.

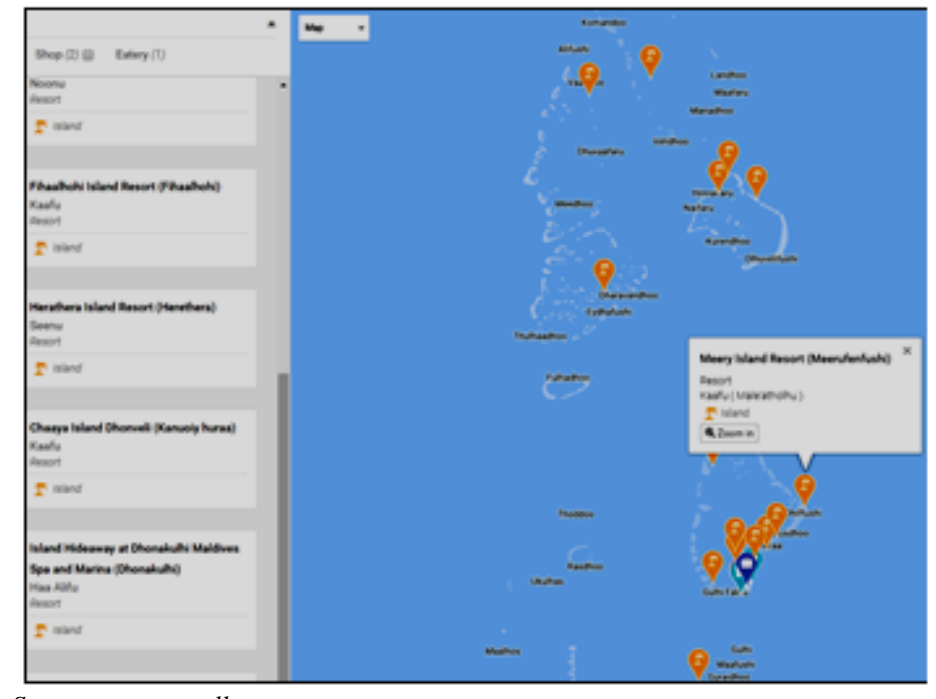

Source: www.eatolls.com

Fig. 9 Example of Geo-tagged Website in Maldives

But Maldives is an island nation consisting nearly 1200 islands located on both sides of the equator. So, if a potential tourist wants to get an estimation of how long will it take to travel from the airport to a particular resort he has to rely on the information provided by the tour agents or the people from the resort. It's hard to collect online information about the sea route by speed boat, ferry or seaplane. These are entirely local data, though valued information for any potential tourist. Eatolls is providing (under process) these kind of Geospatial information in an interactive map interface. Figure 10 depicts the query result of sea route instructions of a particular resort from the International airport.

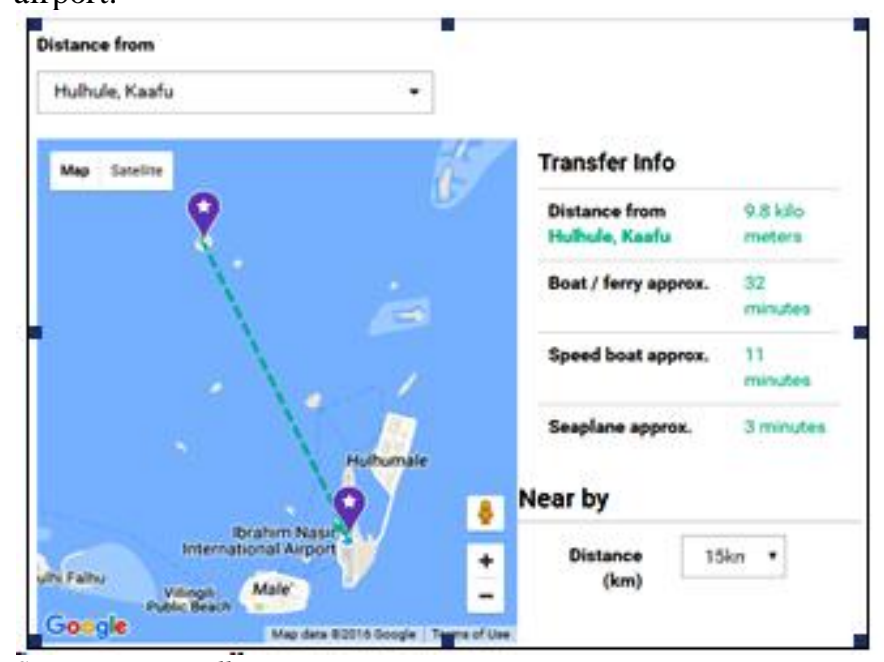

Source: www.eatolls.com

Fig. 10 Directional Information by Geo-tagged Website

Eatolls has also provided some Web 2.0 interface to identify the sea sports or other attractive features nearby using a Geospatial Mashup. Figure 11 is screening the Surfing, Diving etc. popular sea sports features within $15 \mathrm{Km}$ span of the particular resort. This is the query result of the website's metadata repository catalog. These are not only valuable information for any potential toursit, but these act as a promotional factors for those tourist locations and the country as well. Eatolls is providing these sort of Geospatial Web 2.0 information in the geotagged website.

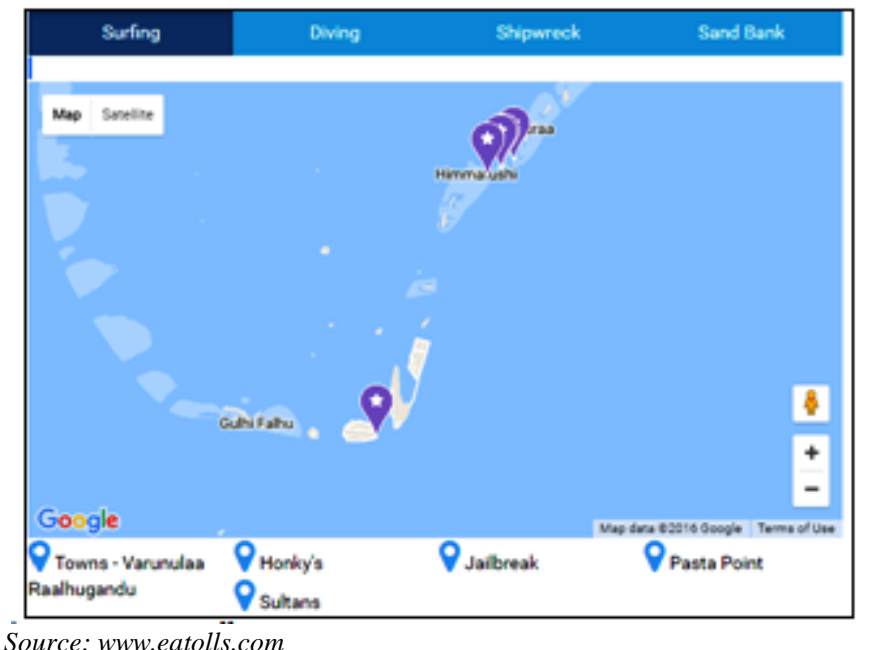

Fig. 11 Metadata Repository by Geo-tagged Website

It can be specified that these type of Geo-tagged websites having Geoportal metadata catalog features definitely add value in terms of geospatial information sharing in a Web 2.0 global platform. It aids not only the potential tourists but it also helps in effective tourism management and executing 
promotional and marketing strategy. Still there is one drawback of this website. It is missing the Public Participation GIS (PPGIS) interface. Like in other geoportals, the common users can contribute and update the available metadata repository. They can create their own map and add in the interactive geospatial mashup. But this website is lagging in that. Though not that much popular, another geotagged website (www.raajjemap.com) of Maldives has provided PPGIS feature. In this geo-tagged website, common users can add placemarks by logging into using some social website credentials. It has the categorized metadata repository for all the atolls and almost all the islands under each attol. Figure 12 is a snapshot of the Rajje Map website depicting the PPGIS and metadata repository features. Any common user can add placemark or road information using the PPGIS Mashup application. That confirms that, online Geospatial information is available and PPGIS feature is also existing for few websites in Maldives. But they are dispersed, not organized in the metadata repository catalog structure. Thus, the geotagged websites and the geoportals are not that much popular and has been under-used.

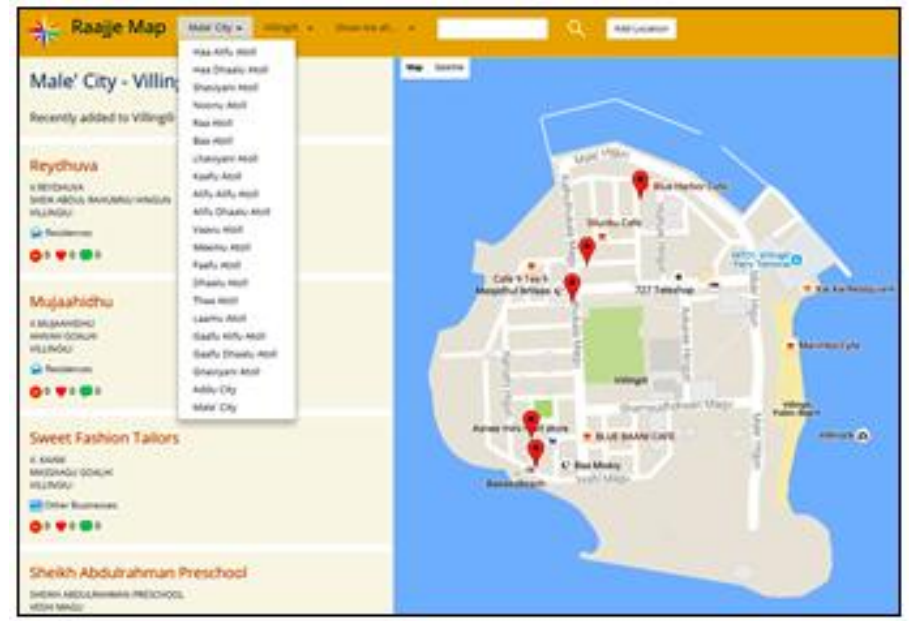

Source: $w w w$. raajjemap.com

Fig. 12 PPGIS features in Geo-tagged Website

\section{GeOPORTAL POTENTIAL IN MALDIVES TOURISM}

The ability to examine data in its spatial context is extremely important. The geocoding process can accept a simple address and matches it to a database containing address ranges for every link in that specific network and provide the result just on a click. A website is no longer a static page in the browser, but a dynamic global platform where the users can create and update their own experiences. Other important aspect of this web as platform is, these websites provide users the access to their data through welldefined user-friendly Application Programming Interfaces (APIs) and hence encourage new uses of the existing data, for example integrating personal data with other existing data sources. Geoportal is a genre of interactive and collaborative Web applications under Web 2.0. It impeccably integrates heterogeneous datasets retrieved from varied Web-based resources to craft innovative Web GIS applications and make the online search faster and interactive. It provides user- friendly platform to access up to date reliable information just on a click and at the same time, provides privilege to the users to share their local information to make it available globally over the Web [29]. At the same time geoportals help in automatic Content Development and Management. Adequate information about a product is one of the key features of promotion and marketing. It is the key driver in tourism marketing also. The creation, aggregation and distribution of creative, innovative and engaging text, imagery and video are at the very core of successful ICTbased tourism marketing. Content-driven marketing is the most cost-efficient and effective form of marketing. However, content development is often the most troublesome component of a tourism marketing campaign. Planning ahead and thinking strategically can create long-term efficiencies in aggregating, developing and distributing content that will be used across all ICT-based tourism marketing platforms [30]. The four key features of a good content in context to tourism marketing are: Compelling, Trustworthy, Efficient and Accessible. Centralized catalogs type of Geoportal provide all these four features in one package. Careful implementation of a centralized metadata geoportal catalog can integrate all the distributed online geospatial information of the island nation of Maldives. Section II of this paper highlights the basic architecture of geoportals. In Section III, the paper discusses and depicts the application of National Geoportals by different countries for tourism management and promotion. Analyzing the user-friendliness and relevancy of national geoportals in the tourism sector, this paper suggests an interactive model to implement a centralized geoportal system for Maldives.

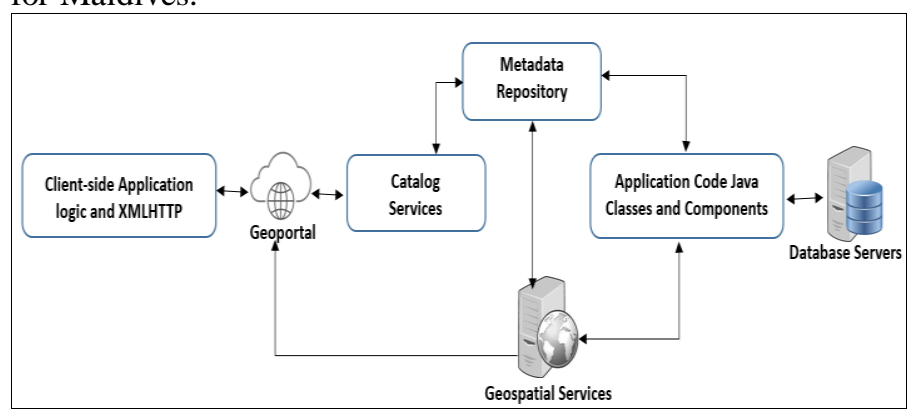

Source: Adapted from www.mycoordinates.org, 2012

Fig. 13 Schematic Model of the Suggested Geoportal

Figure 13 represents the flowchart of the proposed Geoportal model for Maldives tourism.

The dataflow of the system can be summarized as:

- A client (common users or resource providers) can use a browser to execute a query, can be a mobile browser also.

- Client-side logic application and XMLHTTP can process the query and forward it to the Geoportal.

- Geoportal will provide the access point to spatial information on the web. Geoportal will contain the repository links of the online available data.

- Catalogue Services can enable the relevant online metadata repository on the spatial data resources and will search metadata based upon the query criteria. 
- Metadata repository stores the detail information about the online spatial data.

- Geospatial services are the online geospatial service providers, e.g. Google, OpenStreetMap. Usually they provide the base map, the Mashup applications, spatial data retrieval and geospatial representation for the users.

In order to search for the spatial data in the geoportal, users can use web browser and define the search parameters. Then, using the catalog services, the geoportal searches the metadata repositories. Each catalogue service enables the metadata distribution coming from each resource providers. If the server of the relevant data supports the spatial services such as retrieval and display, the user will receive the geospatial information in his browser. The data can be in the form of an interactive Mashup map, can be a set of data files or can be another set of metadata repository. But all categorized and filtered based upon the query parameter provided by the user. The suggested geoportal system will connect the common users and the resource providers in a collaborative platform, called the Geo-network. The common users can also update information using the Mashup applications of the Geoportal. Thus the geoportal will no longer be a static page in the browser, but a dynamic platform where the users can generate and update their own experiences. This geoportal can act as an entry point to access spatial data infrastructures. By providing web-based network services, it can be an essential part of a spatial information infrastructure in Maldives. It can integrate government data along with data from common users and make accessible for the whole community of internet users. In the client-side or browser-side Mashup the geoportals send requests to different services, receives the responses and displays the composite results. The advantage of the metadata catalogs is that, they do not pull the whole data set but just provide the only information about geospatial data, the data owners and the relevant links to access the original dataset. The complete geo-network will have three distinct level of users like any other active geoportals. Fig 14 depicts the different levels of users with their respective functionalities.

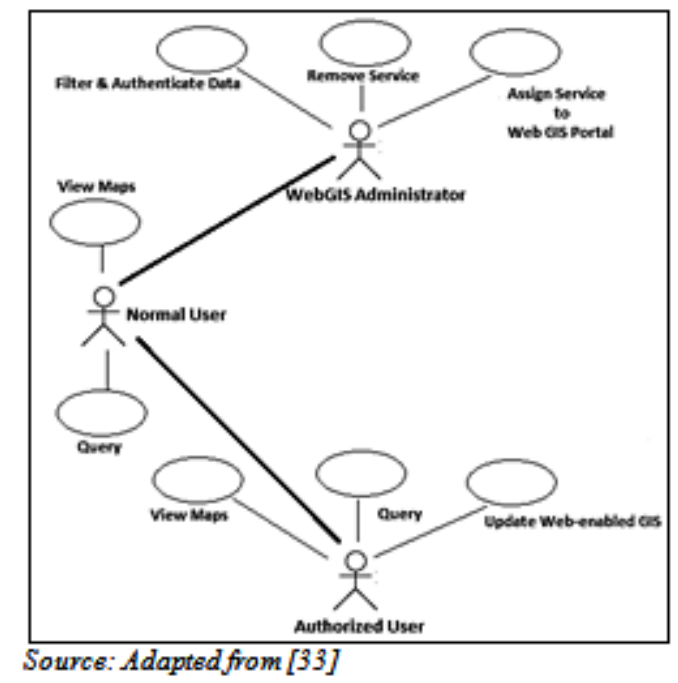

Fig. 14 Level of Users in the Suggested Geoportal Model

In the tourism sector the basic information required by a potential tourist to visit any tourist location is the information of the tourist location, its geographic location, available facilities, transport system, places of interest etc. Initially, the tourists have to depend on the information provided by the travel agents about a location. The agents used to provide the information over telephonic conversation or sharing documents over email. The information may not be up-to-date and the tourists have to solely trust the agents. The tourists could have viewed the aerial imagery maps over the internet, but those maps don't provide detail information about the road, hotels, place of interest, transport facilities available etc. But now with the centralized geoportal system, the tourists can collect detail information about their place of choice. They have to just browse the internet, get into the geoportal, and run a query. They will receive detailed information about the location. Another greatest advantage in this participatory or collaborative geoportals is that, the globally accessible Geo portals are always up-to-date; they contain the most recent information about the location. Even the tourists while visiting those tourist sites if they found something is not matching with the Mashup information over the internet, they can customize those global information with the updated one. This will be beneficial for other potential tourists. These are the benefits of updating information of those locations which are already established as tourist spots. Now, if some entrepreneur or travel agency wants to project a new location as a tourist spot, they can perform initial research work to analyze whether their local area can be developed as a potential tourist destination or not. First and foremost, they have to find out whether that particular location has any Cultural, Ecological or Modern tourism component or not. If it is there they can update that information using the Mashup option in the geoportal. Next, they have to update other facilities like, transport, hotels, café, health service etc. even internet facilities available or not. That means, the locations which can be potential tourist spots can slowly come into limelight just by some simple initiatives taken by the locals. One such online application provided by Google is http://editor.giscloud.com/ where the end users can update and create map online contributing detailed information about their locality or any other place of interest. In this way the geoportals are making hundreds of new Cultural, Ecological or Modern tourist locations popular. This is effecting overall economic development of the location through tourism industry [29]. On the other hand, in today's competitive marketplace, leading companies are analyzing and listening what customers really care about. Traditional forms of marketing are no longer as effective as they used to be in the past. This is where geoportals comes in and allowing the companies to visualize where potential customers are located by analyzing demographic, psychographic, purchasing, and spending characteristics for accurate customer segmentation and helping the companies to find more like them [31]. The suggested geoportal model can create a massive geo-network where collaboration and interoperability are the key 
components to keep the information up-to-date, relevant and dynamic. At the same time the metadata repository and the catalogue services can make the search faster and more effective. Thus, on careful application of this user-friendly, customized geospatial online application it can reach more and more potential tourists in shorter span of time with the most updated information just on a click. According to Tait (2005), the four functions of geoportals, namely Search, Mapping, Publishing and Administrative Capabilities has great implications on trip planning and decision making process. The suggested geoportal model consists of all these features. It can act as the customized information system that provides interactive and collaborative functions including visual presentation about the tourism destination by processing it in an integrated manner on geospatial maps of the tourist site. This fast, collaborative and multi-layer geospatial system can empower the potential tourists of Maldives with new trip planning geospatial tools and information. This suggested geoportal system can act as a virtual guide and planning tool for the potential tourists.

\section{CONCLUSION}

Geoportals provide different opportunities for sharing data collaboratively and using information in new applications and systems. It saves the web from being blogged down in a sea of records and is definitely playing a significant role in the popularity and success of the Web. It is an internet entry point to access spatial data infrastructures. By providing web-based network services, a geoportal is an essential part of a spatial information infrastructure. Geoportal offers the opportunity for federal state agencies, municipal authorities and private companies to make their data and services accessible for the whole community of internet users. The portal is designed to provide only information about geospatial data and the data owners, not the data itself. The data as well as related metadata information remain with the data providers thus leaving full control on all updated information to the information provider [32]. These services are suitable for representing spatial data in a Web 2.0 platform, and since they are globally accepted as standard services, it will be possible to generate a map whose layers are integrated from different geospatial servers. Individual stakeholders responsible for spatial data, will not only get access to facilities to present its data in a customized mode, but also made it possible to search the information spatially by introducing the standard metadata repository catalogue. It can provide instant search access to local and distributed geospatial catalogues by online editing metadata with a potent geo-template system. It can also perform scheduled harvesting and synchronizing metadata repository between distributed catalogues. But like all other technologies geoportals also have few challenges and concerns. New research works are going on to address the following drawbacks. Problems like Security breach, Policy design, evaluation and implementation are serious cases of concern. Issues related to copyright and ownership of shared data and information should also be handled with utmost care. Beside this, how much reliable the uploaded or the shared data is, or the quality of available data etc. are creating some technical and social complications. Finally, there is shortage of technical people to maintain metadata repository and maintaining geo-servers.

A small step in the path of spatial collaborative thinking and working can lead a much faster and dynamic tourism information system for this tourism enriched country. Serious research works and well planned implementation of geoportals, especially in the domain of collaborative and interactive geospatial mashup, metadata repository and geonetwork for Public Participation GIS and enterprise information management will lead a long way towards strategic, interactive and participatory decision making system in tourism promotion and management through reliable and fast information sharing in Maldives.

\section{ACKNOWLEDGMENT}

We would like to thank Mr. MoHAmed IrFan AHMED, Mr. IBRAHIM AZHAD AND MR. JAWAD (eatolls, Male`, Republic of Maldives) for giving their consent to include the snapshot of their website http://www.eatolls.com/. Although any errors are our own and should not tarnish the reputations of these esteemed persons.

\section{REFERENCES}

[1] T. Pierce, G. Dobson and M. Phillips, "GIS Mashups on the Web: Using Google, ESRI, and Open Source to Develop Weather and Climate Applications for the Web," in Conf. Geospatial Infrastructure Solutions, Tampa FL, Apr. 2009

[2] M.F. Goodchild, F. Pinde and P.M. Rich, "Geographic information sharing: The case of the Geospatial One-Stop portal", Annals of Association of American Geographers 97, $2^{\text {nd }}$ ed., 2007, pp. 249-265

[3] A.M. MacEachren and M.J. Kraak, "Research Challenges in Geovisualization", Cartography and Geographic Information Systems, 28th ed. vol 1, 2001, pp. 3-12

[4] Tang, Winnie and J. Selwood, "Spatial portals: Gateways to geographic information", Redlands, Calif: ESRI Press, 2005

[5] M.G. Tait, "Implementing geoportals: Applications of distributed GIS", Computers, Environment and Urban Systems, 29th ed., 2005, pp. 33-47

[6] T.R. Smith and F. James, "Alexandria Digital Library", Communications of the ACM Archive, 38th ed. vol 4, 1995

[7] M.F. Goodchild, Zhou Jianyu, "Finding Geographic Information: Collection level metadata", Geoinformatica, 7th ed. vol 2, 2003, pp. 95112

[8] P. Fu and J. Sun, Web GIS, Principles and Applications, ESRI Press, Ed. 1, pp. $145-146$

[9] FGDC, "Geospatial metadata (2006)", Retrieved from www.fgdc.gov/metadata on 10 Jan. 2016

[10] M.F. Goodchild, "Spatial accuracy 2.0. (2008)", Retrieved from www.geor.ucsb.edu/good/papers/453 on 10 March 2016

[11] M. Hogeweg, "SDI for everyone (2009)", Retrieved from http://martenhogeweg.blogspot.com/2009/10/sdi-for-everyone.html on 20 Dec. 2015

[12] United Nations Working Paper Group Of Experts On No. 34 Geographical Names, "Infrastructure for Spatial Information in Europe (INSPIRE) Status Report on the Development of Implementing Rules for Geographical Names Data (2009)", Retrieved from http://unstats.un.org/unsd/geoinfo/UNGEGN/docs/25th-gegn docs/wp\%20papers/wp34-inspire-germany.pdf on 20 Jan. 2015

[13] Chaudhuri S. and Ray N., "Geospatial Mashups: Internet Based Promotional Tool for Tourism Development", in Conf. 3rd International conference on Innovative Engineering Technologies (ICIET'2016) Bangkok (Thailand), 2016

[14] D. Buhalis, "Strategic use of information technologies in the tourism industry," in Tourism Management, 19th ed. vol. 5, 1998, pp. 409-421. 
[15] Sigala M., "Investigating the role and impact of geovisualisation and geocollaborative portals on collaborative e-learning in tourism education (2012)", Retrieved from www.researchgate.net/publication/257601362 on 20 Nov. 2015

[16] ESRI, "GIS for Marketing: Where Strategy Meets Opportunity (2010)," Retrieved from http://www.esri.com/marketing on 10 Dec. 2015

[17] Jovanovic V. and Njegus A., "The Use of GIS in Tourism Supply and WEB portal development", International Journal on Information Technology (IREIT), $\mathrm{x}$ th ed. vol xx, 2013

[18] Sigala M., "Geoportals and Geocollaborative Portals: Functionality and Impacts on Travellers' Trip Panning and Decision Making Processes", International CHRIE Conference-Refereed Track, 28, 2009

[19] Ilies G. and Ilies M., "Trends in 3D tourist mapping", Geographia Technica, (2), 58 th ed. vol 2, 2006

[20] Layers, LE GOUVERNEMENT (2016), Retrieved from http://map.geoportail.lu/theme/tourisme on 10 Jan. 2016

[21] Turner A., "Introduction to Neogeography", Sebastopol, CA: O'Reilly Media, 2006

[22] Tait, M.G., "Implementing geoportals: applications of distributed GIS", Computers, Environment and Urban Systems, 29, 2005, pp. 33-47 https://doi.org/10.1016/S0198-9715(04)00047-X

[23] World Travel and Tourism Council, "Travel \& Tourism Economic Impact 2016 Maldives", Retrieved from http://www.wttc.org/research/economicresearch/economic-impact-analysis/country-reports/ on 10 March 2016

[24] Ministry of Tourism, Republic of Maldives (2016), Retrieved from http://www.tourism.gov.mv/statistics/annual-publications/ on 20 March 2016

[25] Dowling, R., "The Maldives. In C. M. Hall \& S. Page (Eds.)", Tourism in South and Southeast Asia: Issues and cases. Oxford, UK: Butterworth Heinemann, 2000

[26] Ministry of Housing and Infrastructure, republic of Maldives (2016), Retrieved from www.housing.gov.mv/v1/news/the-final-symposium-formapping-of-the-maldives-and-climate-change-mmcc-project/ on 20 Jan. 2016

[27] ISLES, Republic of Maldives (2016), Retrieved from http://isles.egov.mv/ on 15 Feb. 2016

[28] Tourism Yearbook 2015, Republic of Maldives (2016), Retrieved from http://www.tourism.gov.mv/statistics/annual-publications/ on 20 March 2016

[29] S. Chaudhuri, "Potential of Geospatial Mashups for Tourism Marketing," in Tourism: Marketing A Strategic Approach, Apple Academic Publisher, to be published

[30] COMCEC Coordination Office, "Effective Tourism Marketing Strategies: ICT-Based Solutions for the OIC Member Countries", Retrieved from http://www.mod.gov.tr/Lists/RecentPublications/Attachments/85/Effectiv e_Tourism_Marketing_Strategies,_ICT-

Based_Solutions_for_the_OIC_Member_Countries.pdf on 10 Jan. 2016

[31] A. Auinger, H. Konnerth and N. Dietmar, "Potential of Web-Mashups for Marketing 2.0 Wehrgrabengasse 1-3," 4400 Steyr, Austria, 2008

[32] Mehdi S.A., Ali M., Nima G., Zahra R., Reyhaneh S. and Peyman B., "How to Implement a Governmental Open Source Geoportal (2014)", Retrieved from http://file.scirp.org/Html/1-8401367_48524.htm on 10 Feb. 2016

[33] Chaudhuri S., "Application of Web-Based Geographical Information System (GIS) In E-Business", Handbook of Research on Promotional Strategies and Consumer Influence in the Service Sector, IGI-Global, 2016, pp. 389-405.

https://doi.org/10.4018/978-1-5225-0143-5.ch023 